\title{
ESTILO E ETHOS NA DISNEY: TRANSFORMAÇÕES DA IDENTIDADE
}

\author{
Mário Sérgio Teodoro da SILVA JUNIOR ${ }^{1}$
}

\begin{abstract}
Resumo: Nos últimos anos, a semiótica discursiva ganhou contribuições significativas para o estudo de estilo com Discini (O estilo nos textos, 2013; e Corpo e estilo, 2015), permitindo reflexões sobre a identidade, alteridade e modo de ser do sujeito-enunciador no mundo social e semiótico. A identidade dos estúdios de animação Walt Disney é uma das mais persistentes temporalmente, com mais de 70 anos de carreira e de grande popularidade. No presente trabalho, pretendemos explorar como um estilo pode permanecer tão constante e atual ao longo de tanto tempo. Além dos desenvolvimentos das questões de ethos e estilo em Discini, recorreremos à conceitualização de ethos proposta por Maingueneau (Novas tendências em análise do discurso, 1997; A propósito do ethos, 2008). Selecionamos três trailers de filmes da Disney, recobrindo o período de 1942, com o trailer de Bambi, a 1992, com o trailer do musical Aladim, e a 2013, com Frozen: uma aventura congelante. Assim, podemos observar como o enunciador Disney constrói, no enunciado, um mundo exemplar de que faz parte, como define seu enunciatário e como define o estilo outro ao qual não se identifica, expressando, assim, um posicionamento ético no mundo social.
\end{abstract}

Palavras-chave: Estilo. Ethos. Semiótica.

\section{Introdução}

Hoje em dia, dificilmente a homogeneidade persevera. Em outras palavras, com o advento da comunicação instantânea e a ascensão dos grandes meios de comunicação, das grandes mídias (televisão e internet), a diversidade é colocada em evidência constantemente. No caso da ficção cinematográfica, trata-se da diversidade de gênero, de

\footnotetext{
${ }^{1}$ UNESP - Universidade Estadual Paulista “Júlio de Mesquita Filho” - Programa de Pós-graduação em Linguística e Língua Portuguesa. Araraquara - São Paulo - Brasil. 14800-901 mario.teodorojr@fclar.unesp.br
}

http://dx.doi.org/10.21165/gel.v13i3.134 
autoria, de atores, em suma, diversidade de estilos. A impressão que se tem é de que não existem estilos velados no Cinema, mas de que tudo é prestigiado pela grande tela.

Dentre os grandes nomes hollywoodianos, como Universal, Warner Bros., Sony e Fox, que cobrem vários estilos ficcionais, uma empresa específica demonstra o grau mais visível de recorrência e concisão: a Walt Disney. A Disney pode ser levada em conta sob perspectivas mais ou menos amplas, a depender do objetivo do analista. A companhia é dona de várias marcas, tais como canais de televisão, a Pixar (que produz animações “3D”, ao estilo de Toy Story e da sua concorrente DreamWorks), a Lucas Film (estúdio de Star Wars), o estúdio Marvel (responsável pelos blockbusters de super-heróis de nossa década, Homem de Ferro, Vingadores e afins), além de produzir filmes live-action (com atores humanos) por meio de uma série de outras subsidiárias, distribuidoras, etc. Por fim, ela também é dona dos estúdios de animação, seu centro e origem, que produziram os 53 longas-metragens que são o escopo de nosso trabalho.

É claro que poderíamos identificar algumas recorrências de traços em todas as grandes empresas hollywoodianas, mesmo que suas produções sejam diversas. A DreamWorks, que produz, essencialmente, animações como Shrek e Madagascar, tem, inequivocamente, um estilo definido, mas sua fundação é consideravelmente recente, da metade dos anos 1990. O caso da animação Disney é diferente de tudo já visto pela “cultura de massa” por sua persistência temporal. Walter Elias Disney iniciou-se em Hollywood com curtas-metragens animados produzidos ao longo dos anos 1930, conhecidos como Silly Symphonies, e, em 1937, estreou no ramo dos longas-metragens com Branca de Neve e os sete anões. Até hoje, os estúdios produzem longas animados, e todos mantêm um estilo latente. Não é de se admirar podermos dizer “estilo Disney” e sermos entendidos sem carecer de uma explanação teórico-técnica avançada, ou que as pessoas digam “isso é a cara da Disney” sem medo de incompreensão, ou ainda, quando a empresa comprou a Marvel e a Lucas Film, falou-se que os super-heróis e Star Wars passariam a agir conforme o jeito Disney. Disney não é apenas substantivo, é adjetivo, e por isso distingue-se de outras companheiras de mercado.

A questão é: será que esse estilo é tão sólido como se demonstra para o público? Como permanecer fiel a seus princípios, a sua identidade, por mais de 70 anos, em um mundo em que a transformação e a diversidade são tão presentes, em um mundo em que a homogeneidade não costuma perseverar, em que ela sempre se atualiza? 
De certo, a questão de ethos, a partir das proposições de Maingueneau, parece a mais precisa para tratarmos desse tema, a ser complementada pelos estudos recentes de Discini acerca de estilo, que parte do ethos e chega a reflexões caras à semiótica discursiva brasileira contemporânea. Por questões de extensão, não é possível trabalhar com filmes inteiros em um artigo. Logo, parece propício o uso dos trailers de alguns filmes para começar a postular considerações sobre o estilo Disney. Para tanto, selecionamos um trailer de Frozen (Frozen: uma aventura congelante, blockbuster de 2013 (2014 no Brasil)), o trailer de época de Aladdin (Aladim, 1992), que marca o período do início dos musicais Disney, de sucesso avassalador (o predecessor de Aladdin, A Bela e a Fera (1991), foi a primeira animação a ganhar o Oscar de melhor filme, quando não havia sequer a categoria “melhor animação”), e o trailer de época de Bambi (1942), que recebeu o toque direto do homem Walt Disney, no início do longo percurso dos estúdios.

É preciso ressaltar que os trailers serão apreendidos segundo elementos essencialmente verbais que instituam a ética Disney, procedimento que exclui uma análise do enunciado sincrético dos objetos do trabalho.

\section{Tópicos teóricos}

É preciso que pontuemos a conceitualização de ethos e os tópicos que nos serão pertinentes no tocante à reconstrução da imagem do enunciador e do estilo enunciativo desses textos. O ethos discursivo, tomado a partir dos trabalhos de Maingueneau (2010), termo ressignificado a partir do ethos da retórica clássica, aponta para o caráter do enunciador, salientando sua voz e seu tom, mas também coloca em foco o papel do dito fiador, o enunciatário, e o modo como este constrói, na enunciação, a imagem ética daquele que enuncia.

A noção de corpo também é inserida e complexifica o conceito.

Mas o tom por si só, não recobre, em seu conjunto, o campo do ethos discursivo. O tom está necessariamente associado a um caráter e a uma corporalidade. O "caráter" corresponde a este conjunto de traços "psicológicos" que o leitor-ouvinte atribui espontaneamente à figura do enunciador, em função de seu modo de dizer. [...] não se trata aqui de caracterologia, mas de estereótipos que circulam em uma cultura determinada. Deve-se dizer o mesmo a propósito da "corporalidade", que remete à representação do enunciador da formação discursiva. 
Corpo que não é oferecido ao olhar, que não é uma presença plena, mas uma espécie de fantasma induzido pelo destinatário como correlato de sua leitura. (MAINGUENEAU, 1997, p. 46-47)

Vê-se que o termo não se resume a um corpo físico, porque ethos não se trata, afinal, de uma maneira de ler o mundo natural ${ }^{2}$, mas sim de ler o mundo discursivo. Por isso, referimo-nos a corpos semióticos unicamente. Já a incorporação é um processo pelo qual o enunciatário toma noção e forja para si o tal corpo semiótico:

Propus designar com o termo "incorporação" a maneira como o intérprete - audiência ou leitor - se apropria desse ethos. Convocando de maneira pouco ortodoxa a etimologia, podemos fazer render essa "incorporação" sob três registros:

— a enunciação da obra confere um "corporalidade” ao fiador, ela lhe dá corpo;

- o destinatário incorpora, assimila um conjunto de esquemas que correspondem a uma maneira específica de se remeter ao mundo habitando seu próprio corpo;

- essas duas primeiras incorporações permitem a constituição de um corpo da comunidade imaginária dos que aderem ao mesmo discurso. (MAINGUENEAU, 2008, p. 18)

Trata-se, além, também de um policiamento da própria existência corpórea do enunciatário, prevista pelo enunciado, uma vez que o enunciador permite a seu públicoalvo habitar seu mundo ético (MAINGUENEAU, 2008, p. 18). Se o mundo natural diz respeito à existência física e historicamente marcada dos sujeitos de carne e osso, o mundo ético é relativo à construção psicológica de um universo exemplar e ideológico existente apenas no discurso, uma utopia feita de linguagem.

Cria-se, assim, a imagem final de um coletivo de enunciatários que partilham essa mesma tática de habitar o corpo e o mundo semióticos, estereotipada e disseminada culturalmente no circuito sociocultural dos discursos. Dessa forma, os ethe constituemse em estereótipos de voz, de tom e de corpo. Esses estereótipos são encontrados ao analisar o discurso Disney: o ethos do enunciador, do enunciatário e de um terceiro corpo, aquele que não é como o enunciador nem partilha do mesmo mundo ético: “O orador enuncia uma informação e, ao mesmo tempo, diz: eu sou isto aqui, não aquilo lá” (BARTHES apud MAINGUENEAU, 2008, p. 13).

\footnotetext{
${ }^{2}$ Mundo natural, em abordagem semiótica, equivale ao mundo real apreendido pelo homem real, figurando sempre como certo referente do enunciado (Cf. GREIMAS; COURTÉS, 2013, p. 324).
} 
A ideia deste outro é crucial na compreensão da proposta de estilo de Discini (2013, p. 28-29):

Para entender o estilo, deve-se prender à imagem-fim do ator da enunciação de uma totalidade de discursos enunciados. Essa imagemfim, simulacro reflexivo, ou seja, imagem construída do ator para si mesmo, é também um simulacro hétero-construído, supondo a visão que tenho do outro, bem como a visão que penso que o outro tem de mim. Essa imagem-fim, orientada pelo rumo tímico de uma totalidade, segue então um contínuo na construção do efeito de individuação, mas esse contínuo se apóia num descontínuo, ou seja, nos níveis do percurso gerativo do sentido. O estilo, portanto, fundamenta-se num simulacro, é reconstruído por outro: o percurso gerativo de sentido que, por meio da narratividade e do discurso, reconstrói a geração do sentido da totalidade, para aumentar a inteligibilidade dessa mesma totalidade.

O rumo tímico, a foria, pode ser estabelecido pela relação dos termos eufóricos, “eu” e "tu”, enunciador e enunciatário, que partilham uma identidade complementar, e dos termos disfóricos, o outro, contrário ao “eu”, porque com ele estabelece alteridade, e subcontrário ao "tu”, pois com ele deixa de estabelecer identidade. Esses termos podem ser dispostos em um quadrado semiótico (ver gráfico 1$)^{3}$.

\section{Gráfico 1 - Quadrado semiótico da identidade no jogo enunciativo}

$\mathrm{Eu}$<smiles>CCCCCCCC</smiles>

$\mathrm{Tu}$

(não-alteridade)
Outro

(alteridade)

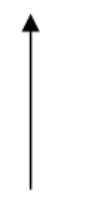

Outro

(não-identidade)

O ponto interessante em se colocar os termos nesse tipo de relação é notar como o enunciatário “tu” não é passivo à identidade do enunciador “eu”, isto é, “tu” não é

\footnotetext{
${ }^{3}$ Os dois termos referentes à imagem do "outro", um ator que se difere, ao mesmo tempo, de "eu" e de "tu”, também se diferem entre si. O "outro" da alteridade é oposto à identidade de "eu". O "outro" da nãoidentidade é um eufemismo do primeiro. Tratando-se de um percurso modalizante, este segundo "outro" PODE, mas não-SABE assimilar os traços identitários de "eu”, enquanto o primeiro não-QUER assimilá-los, porque é contra essa maneira de habitar o mundo ético.
} 
contrário, não é “outro”, mas está aquém da identidade, precisa ainda ser convencido, fortificando o aspecto argumentativo da enunciação. Por outro lado, se "tu” está a um passo da identidade de “eu”, também está totalmente desligado de “outro”, porque dele é contrário e contraditório. Os “outros” jamais se deixam convencer por “eu”, por não quererem ou não saberem, a depender das modalidades envolvidas no percurso narrativo subjacente, enquanto "tu" escuta e assiste ao filme, aderindo ao mundo ético do enunciador.

Quando o enunciador aponta para o “outro” não só diz que é diferente deste como também, ao apontar para "tu”, diz que “outro" e "tu” são diferentes entre si, criando a conduta exemplar a ser seguida por “tu”, diferente da conduta do “outro”, termo disfórico e não-identitário.

Um dos pontos centrais da argumentação de Discini é o sentido tomado na totalidade de enunciados, como vimos anteriormente. O estilo resulta do liame semiótico entre discursos familiares: "Deve-se buscar o estilo na configuração interdiscursiva de uma totalidade de discursos enunciados.” (DISCINI, 2013, p.28).

A dinâmica entre totalidade e unidade é sistematizada pela oposição da dita Unidade integral (Ui), o unus, o enunciado, e a Unidade partitiva (Up), o nemo, o nãoenunciado, que se negam, respectivamente, em Totalidade partitiva (Tp), o omnis, o conjunto de discursos não identitários, e em Totalidade integral (Ti), o totus, o conjunto de enunciados identitários. Dessa forma, temos o percurso Up/virtualização $\rightarrow$ Ti/atualização $\rightarrow$ Ui/realização $\rightarrow$ Tp/potencialização $\rightarrow$ Up/virtualização (Cf. DISCINI, 2013, p. 34-35). O que nos autoriza a falar em estilo da totalidade a partir da análise de unidades é a ideia de que "O todo está nas partes e vice-versa, ao se tratar de qualquer estilo" (DISCINI, 2013, p. 48).

Unus e totus estão integrados. Os simulacros de identidade e alteridade são construídos no nível da totalidade, de onde também corporifica-se o ethos, mas os efeitos de sentido que daí despontam encontram-se na geração do sentido da unidade integral, pois nela residem os signos que se repetem, criando isotopias. As isotopias, também chamadas de configurações discursivas (Cf. GREIMAS; COURTÉS 2013, p. 87-89), respaldam sistematicamente as impressões de leitura.

Um certo estoque de configurações discursivas é elemento catalisador do fato de estilo. Em cada configuração discursiva, detectam-se, nesse 
caso: um núcleo figurativo comum; invariantes temáticas; variações figurativas; variações temáticas; papéis configurativos, sendo que estes últimos se constituem por uma "forma temático-narrativa". [...] Nessas isotopias figurativas e temáticas e nesses papéis configurativos, firmase a recorrência e firma-se a unidade, mas firma-se também o diálogo, pois daí desponta a convergência ou a divergência com as vozes de um dado contexto sócio-histórico. (DISCINI, 2013, p. 65)

Esse repertório de revestimentos discursivos, temas e figuras, e de papéis narrativos e temáticos, subjacente a uma totalidade de discursos, configura as possibilidades enunciativas. No caso dos estúdios de animação Disney, é o modo como eles costumam enunciar, firmado por sua tradição de mais de cinquenta anos de repetição dessas configurações discursivas.

Notamos como a Unidade partitiva, "fato de estilo", é referida como produto de abstração da presença de um ethos em conteúdo memorizável socialmente:

A partir do todo potencializado, a unidade virtual projeta-se, em princípio, como "parte reconhecível" e "constituinte do conjunto" [...].Conforme um "conteúdo da memória” firmado como abstração feita da integralidade ou como abstração feita da carne discursiva, compatível com a atualização e com a realização da quase-presença, dáse a ver a unidade virtual. [...] O fato de estilo expressa, como enunciado formal, o que é recorrente nas moralizações relativas ao perfil social do ator. (DISCINI, 2015, p. 59-60)

Podemos articular as unidades e as totalidades propostas por Discini inserindo a acepção de estereótipo de Maingueneau no lugar da Unidade partitiva, que se trata, afinal, de “uma representação difusa” proveniente da abstração feita do filme pelo enunciatário no processo dinamizante de estilização e estereotipação (ver Gráfico 2). 
Gráfico 2 - Percurso do estilo formulado a partir de Discini (2015, p. 57)

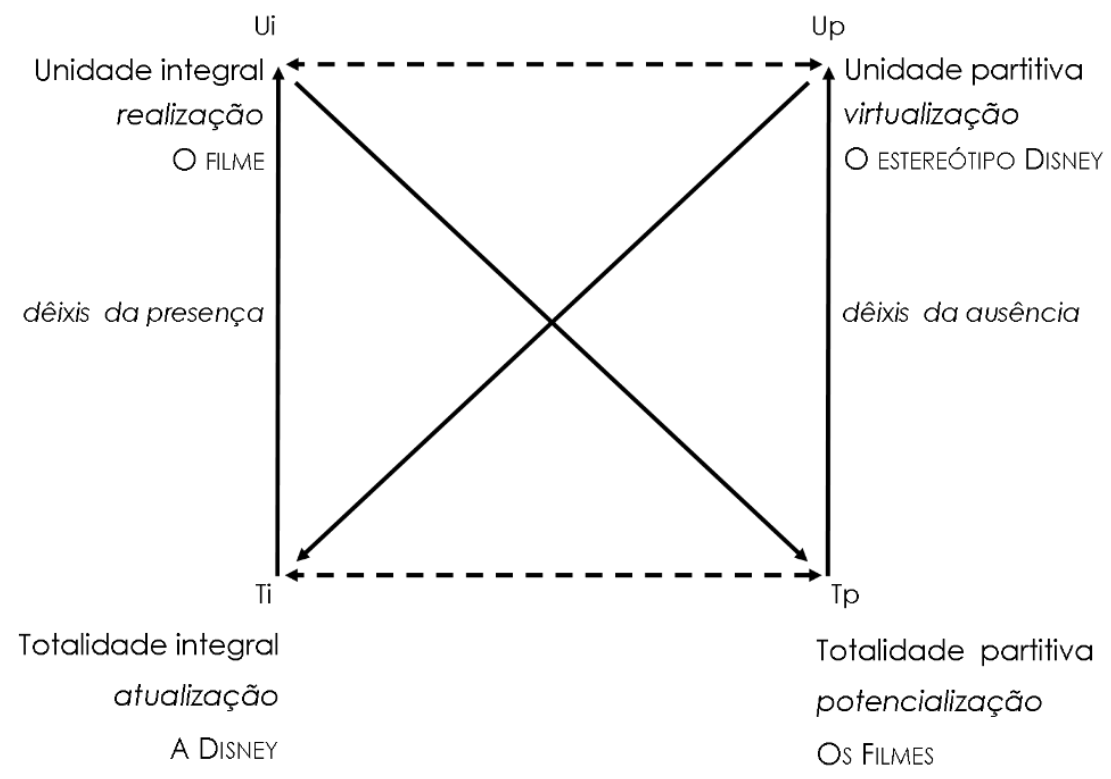

Observe-se a negação da Unidade integral (Ui), de máxima densidade da presença corpórea do ethos, em Totalidade partitiva (Tp), em que as semelhanças entre os enunciados são potencializadas, resultando em um conjunto de filmes distintos. De Tp afirma-se a Unidade partitiva (Up), o fato de estilo de Discini que associamos ao estereótipo de Maingueneau, pois trata-se de uma forma difusa de fácil circulação no meio social, sempre virtual. O estereótipo é atualizado em Totalidade integral (Ti), em que os enunciados se unificam segundo seu estilo, ganham um arquienunciador preciso, um ethos denso e, em nosso caso, é também o momento em que ganham a assinatura Disney pelos estúdios de animação. Por fim, a totalidade se realiza novamente em Ui, o filme propriamente dito, a origem e o fim de um percurso da abstração/generalização à densificação/especificação.

\section{Bambi (1942)}

Comecemos pelo trailer mais antigo, de $\mathrm{Bambi}^{4}$, filme que estreou em 1942, logo no início da carreira de Disney, o quinto longa animado, após Branca de Neve..., Fantasia, Pinóquio e Dumbo (SURRELL, 2009).

\footnotetext{
${ }^{4}$ O trailer, no original em inglês, está disponível para reprodução no YouTube. Disponível em: $<$ https://www.youtube.com/watch?v=nLvX-erABqY>. Acesso em: 25 jul. 2015.
} 
O trailer inicia-se com uma estante de livros e uma frase que aparece escrita: “Aclamado por mais de 10.000.000 de leitores! Um livro da seleção do Month Club... Se torna o maior filme do ano.”, e o livro Bambi, de Felix Salten, aparece saindo da estante. Então, o enunciador diz "Walt Disney, o maior contador de histórias do mundo, traz para a tela a maior história de amor do mundo: Bambi, uma história que prova que o amor pode ser recheado de risadas.”. Os personagens aparecem conversando em uma cena em que o personagem da coruja explica o que é o amor, e os outros animais aparecem apaixonando-se pelas suas fêmeas. O enunciador retoma a palavra e diz "Bambi, a história de um jovem cervo que aprende que o amor significa muitas coisas para muita gente. Para os seus pais, significa coragem e sacrifício. Para a companheira de Bambi, Faline, o amor é, ao mesmo tempo, doce e assustador. Para Bambi, o amor vem a significar heroísmo e bravura. Agora, saindo da floresta, a mais forte, eletrizante e romântica história jamais trazida para as telas por Walt Disney.” (tradução nossa) ${ }^{5}$.

Notamos um fato interessante de antemão, o ator da enunciação não é Walt Disney, tampouco se nomeia como Disney, mas coloca-se como uma pessoa à parte, um “eu” que reconhece o ator Walt Disney, a quem ele se dirige como "greatest storyteller”, o maior contador de histórias. Walt Disney é mostrado, então, como um “outro”, mas não um “outro” disfórico, um “outro” eufórico, que não rearranja a timia acerca de “eu” e “tu”, mas é posto, na narratividade enunciativa, como um sujeito de quem o enunciatário é manipulado a estar conjunto. Na realidade, a manipulação é para que o enunciatário esteja em conjunção com o filme Bambi, para que ele assista ao filme. Walt Disney, o homem, é o sujeito que já está conjunto desse objeto, porque é quem o produziu, logo, é uma figura, um sujeito-figurativo, que deve ser exemplo de conduta para o enunciatário, assim como serve de exemplo de conduta para o enunciador, que se refere a ele com entusiasmo.

A conduta aqui referida ocupa o papel de outro objeto-valor, mais disseminado e menos figurativo, baseada em elementos elencados ao longo do texto: amor, riso,

\footnotetext{
${ }^{5}$ Acclaimed by more than 10,000,000 READERS! A BOOK OF THE MONTH CLUB Selection... _BECOMES THE PICTURE Of the Year! Walt Disney, the world's greatest storyteller, brings the world's greatest love story to the screen: Bambi, the story that proves that love can be loaded with laughs Bambi, the story of a deer that learns that love means many things to many people. To his parents it means courage and sacrifice. To Bambi's mate, Faline, love's at once a tender and a terrifying thing. To Bambi himself, love comes to mean heroism and fearlessness. Here, searching out of the rowing forest, the most powerful, thrilling and romantic story every brought to the screen by Walt Disney.
} 
coragem, sacrifício, ternura, susto, etc. Eles podem ser abstraídos em dois tipos de conduta, uma extremamente altruísta, que suscita o esforço desmedido para ajudar ao próximo, e uma sensível, voltada à valorização eufórica das paixões. Ambas remetem à intensidade (intensidade no altruísmo e na sensibilidade) porque nada mostrado no trailer é neutro neste aspecto. Pelo contrário, ou algo é muito bom ou é muito ruim, ou é muito arriscado ou é muito prazeroso, mas sempre é “muito”, intensificado e exagerado.

Essa maneira de habitar o mundo ético a que o enunciador pertence é a conduta do ethos Disney, gerador de um viver intensamente, arriscadamente, prazerosamente, sem lugar para a neutralidade, para a indisposição ou para a passividade em relação aos outros sujeitos, ao espaço e a si próprio. Levando a reflexão além, se o mundo ético apresentase como o maior objeto-valor, o filme, dessa forma, pode ser rebaixado a objeto-modal. Assistir ao filme tornar-se-ia um programa narrativo de uso, cujo programa narrativo de base é o sujeito entrar em conjunção com $\mathrm{O}_{\mathrm{v}}$-mundo ético.

Basicamente, do ponto de vista da enunciação, esses são os elementos que mais nos interessam nos trailers, sem querermos nos aventurar na compreensão do esquema narrativo desenvolvido pelos outros atores e sujeitos narrativos, pois esse exercício seria melhor efetuado mediante a análise do próprio filme. De qualquer forma, já identificamos, pelo jogo argumentativo entre enunciador e enunciatário, uma série de temas de caráter do ethos, além de seu mundo ético objetivado.

\section{Aladdin (1992)}

Depois de Bambi, a Disney passou por outros períodos variados. A inovação de Walt deixou de ser novidade, e, apesar de seus filmes manterem-se bem-sucedidos, logo após a sua morte, em 1967, a empresa entrou em uma crise tanto administrativa como artística. O pior período financeiro se estendeu, e poucos filmes da época entre 1970 e 1980 são conhecidos hoje em dia (STEWART, 2006), por mais que se possa perceber que, em termos de conteúdo e de expressão, eles não se diferenciem muito dos grandes sucessos (SURRELL, 2009), o que nos coloca em conflitos muito mais políticos do que propriamente semióticos.

A sorte dos estúdios mudou em 1984 (STEWART, 2006), com uma nova gerência assumindo todo o conglomerado empresarial Disney e uma nova gerência e pessoal que 
iniciou seus trabalhos nos estúdios de animação, dentre os quais se destacam Jeffrey Katzenberg, presidente do conselho dos estúdios de animação, que mais tarde fundaria a DreamWorks, Howard Ashman, letrista e ganhador de Oscar de melhor canção por $A$ pequena sereia e A bela a fera, que faleceu logo em 1991, antes de ver seu último filme estrear, e Alan Menken, músico, associado aos estúdios até hoje e corresponsável pelo sucesso musical ao lado de Ashman, além de uma série de outros nomes cruciais ao período (WAKING sleeping beauty, 2009). Note-se que escolhemos citar o núcleo musical de Ashman e Menken porque a música, na animação a partir de 1989, foi e é o grande diferencial Disney.

Quanto ao trailer ${ }^{6}$, ele se inicia com o logo da Walt Disney Pictures e com uma recapitulação dos dois últimos filmes da Disney, com suas respectivas trilhas sonoras tocando, enquanto vemos imagens deles e o enunciador diz: "Há três anos, levamos vocês a uma mágica jornada debaixo do mar. No último ano, levamos vocês para um lugar onde uma linda garota olhou dentro do coração da fera e encontrou o homem dos seus sonhos. Agora, venha conosco e entre em um mundo totalmente novo além da sua imaginação, onde um garoto descobre uma lâmpada e um gênio que pode fazer todos os seus sonhos virarem realidade.”. Os personagens de Aladdin tomam a palavra reproduzindo uma cena, ao som da trilha sonora, e, em seguida, a voz do enunciador retorna: “A Walt Disney Pictures apresenta 'Aladim'”, e continua: “Imagine um mundo totalmente novo de empolgação, perigo e encantos. É a história de um menino pobre das ruas e uma linda garota de um palácio. Eles eram duas pessoas muito diferentes colocadas juntas graças a um desejo incrível”. Na sequência, o gênio transforma Aladim em um príncipe, ao som de outra canção da trilha sonora, e o trailer mostra trechos de uma terceira canção. "Mas o feiticeiro do mal, Jafar, descobriu o segredo do poder de Aladim e não vai parar por nada até roubá-lo. Imagine o mundo a seu comando apenas para descobrir que o verdadeiro poder está dentro de você. ‘Aladim’, com seis novas músicas do compositor ganhador do Oscar com 'A pequena sereia' e a 'A bela e a fera'. Vindo neste fim de ano, ‘Aladim', da Walt Disney Pictures.” (tradução nossa). ${ }^{7}$

\footnotetext{
${ }^{6}$ O trailer, no original em inglês, está disponível para reprodução no YouTube. Disponível em: <https://www.youtube.com/watch?v=QapaqcDucmg>. Acesso em: 25 jul. 2015.

${ }^{7}$ Three years ago, we took you on a magical journey under the sea. Last year, we took you to a place where a beautiful girl looked into the heart of the beast and found the man of her dreams. Now, come with us and enter a whole new world beyond your imagination, where a boy discovers a magic lamp and a genie who can make all his dreams come true. Walt Disney Pictures presents “Aladdin”. Imagine a whole new world
} 
Fica claro que a música é crucial, uma vez que a trilha é muito explorada ao longo do trailer, o que dá à Disney uma identidade musical. É uma música que, como qualquer outra peça musical, tem seu sentido semântico convencionado pela prática discursiva a ela ligada. No caso da Disney, era, a princípio, uma música com ritmo forte, orquestrada, com muitos sons metálicos e/ou de cordas, sempre com uma peça menos estridente e mais delicada necessariamente ligada a uma cena ou de amor ou de um tom muito mais sério. Com o tempo, o sentido dessa música funde-se ao ethos Disney, resultando em sons que atribuímos a esse tipo de filme e que, quando utilizados, reforçam a memória cultural que já se tem deles e de suas canções.

Do ponto de vista dos sujeitos da enunciação, vemos, primeiramente, que o homem Walt Disney já não é referenciado, e sim os estúdios, representados pela figura da Walt Disney Pictures, e o enunciador não se diferencia desse outro sujeito, mas juntos, os dois são um só, um coletivo que reflete a numerosidade de profissionais que produzem esses filmes-objeto-valor. Por outro lado, um “tu” é explicitado (“you”), que, em inglês, é tanto plural como singular. Na tradução livre que fizemos, tomamos escolhas que são arbitrárias, mas que, sem dúvida, salientam tanto a pluralidade do enunciatário como o apelo íntimo, que elenca apenas um sujeito como fiador.

Quanto ao mundo ético e a maneira de habitá-lo, aquela conduta da intensidade é mantida, porque se trata de um mundo (e o trailer usa a palavra mundo, world, que também dá título a uma das canções “A whole new world”) de empolgação, de perigo e de encanto, porque as cenas mostram muita ação, porque o Gênio é um ator exagerado em tom de voz e em expressões gestuais, porque a própria ideia da magia é suscitada como uma magia espalhafatosa, etc. E, se em Bambi havia nuances da diversidade desse mundo ético, como, por exemplo, a forma como o amor ganhava diversas acepções para cada ator do enunciado, agora, a diversidade é explicitada conforme o contraste entre o menino e a princesa é salientado. Quando a frase que recupera a história de A bela e a fera sugere que a maneira de habitar o mundo é “olhar dentro do coração”, Aladdin põe em jogo a questão do poder mágico e do verdadeiro poder encontrado dentro do ator

of excitement, danger and enchantment. It's the story of a poor boy from the streets and a beautiful girl from a palace. They were two very different people brought together by one incredible wish. But the evil sorcerer Jafar has learned the secret about Aladdin's power and he'll stop at nothing to steal it away. Imagine the world at your command only to discover that the greatest power is within. "Aladdin", featuring six new songs from the Academy Award-winning composer of the "Little Mermaid" and "Beauty and the Beast”. Coming this holiday season, Walt Disney Picture’s “Aladdin”. 
(within), trilhando o percurso temático de união das diversidades: diverso por fora, idêntico por dentro, porque o morador de rua e a aristocracia enamoram-se, e fraco por fora, forte por dentro, porque o gênio não é a solução dos problemas, e sim a imaginação. Por fim, a imaginação é explicitada como atitude eufórica.

\section{Frozen (2013)}

Finalmente, se dissemos que a música “foi e é” o grande diferencial Disney, é porque, do final dos anos 1990 para cá, os estúdios não mais investiram em musicais. Depois do sucesso de O rei leão, Katenzeberg desvinculou-se da Disney, e Ashman já havia falecido havia 3 anos. Por algum motivo, Pocahontas, musical de 1995, não obteve maior bilheteria que seu antecessor e os títulos animados caíram em popularidade gradualmente, até que a música foi, também gradualmente, retirada e rearranjada nos filmes. Nos anos 2000, a primazia não foi musical. Na verdade, atores do enunciado não mais cantavam canções e a música deixou de ser usada enuncivamente para ocupar papel apenas na enunciação, isto é, ouvem-se músicas cantadas por atores da enunciação diferentes do enunciador, e que só o enunciatário ouve. São músicas que não participam dos percursos narrativos dos personagens.

Entretanto, na penúltima cerimônia do Academy Awards, o Oscar, de 2014, a atriz Idina Menzel cantou para o público a canção Let it go, do filme de animação Frozen, no qual ela foi dubladora. Let it go foi premiada com o Oscar de Melhor Canção Original e Frozen, com o de Melhor Filme de Animação, tendo uma repercussão espantosa mundo afora. A música retornou em um filme musical completo, em que os personagens cantam e escutam o som.

Encaminhando-nos ao trailer $^{8}$, não há um enunciador que tome a palavra sobre ou pela Disney, mas um enunciador que conta a história do filme. O verdadeiro enunciador-manipulador, que vai vender o filme, se vale da fala desse primeiro, mas não chega a falar oralmente, aparecendo em palavras escritas na tela, encaixadas entre as cenas selecionadas. Primeiro, aos 56 segundos, lemos “A Disney APRESENTA”, depois, de 1min26s em diante “A AVENTURA, A MAGIA, A MÚSICA.”. E a trilha Sonora

\footnotetext{
${ }^{8}$ O trailer, no original em inglês, está disponível para reprodução no YouTube. Disponível em:

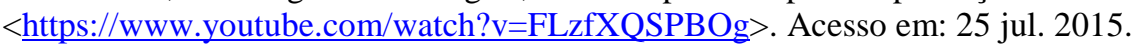


começa a tocar: "VIVENCIE O MAIOR EVENTO ANIMADO DA DISNEY DESDE “O REI LEÃO”. DOS CRIADORES DE “ENROLADOS”, NESSE FIM DE ANO, O PODER DA FAMÍLIA É A MAGIA MAIS FORTE DE TODAS” e o trailer termina com o logo do filme e o nome dos estúdios “DISNEY 'FROZEN”” (tradução nossa) ${ }^{9}$.

A música, como em Aladdin, tem muita importância, o viver intensamente também é explorado, a magia e a força interior e, dessa vez, o termo “família” entra na equação, trazendo à tona uma série de valores sociais que circulam nessa que é uma das instituições mais presentes e comuns em todas as culturas. Dizer que a família é importante, ainda mais quando se tem um filme que será chamado de "filme familiar", é valorizar aspectos do caráter do enunciatário, é uma estratégia de convencimento, mas é, sobretudo, um traço ético do fiador que o enunciador incorpora em seu ethos, e isso acontece, na Disney, a partir do momento em que esse enunciador toma consciência de que seu objeto-valor, o filme, é vendido para famílias porque se encaixa no modo de ser da família standard mundial ${ }^{10}$.

Familiar é um termo que também aponta para outras várias características que regem o comportamento social nos EUA, no Brasil e em uma porção de outros países e comunidades. Logo, junto do campo semântico de "família” está uma conduta social muito difícil de ser definida porque ela está infinitamente disseminada em toda a vida como a conhecemos e no lugar de onde enunciamos.

Por outro lado, “família” também remete a princípios de união, principalmente no que diz respeito a Disney e a Walter Disney, em um país em que a família é privilegiada em todas as esferas públicas. A união da família, esse ideal semiótico, estende-se, na Disney, à comunidade e nos coloca de volta no lugar comum do altruísmo de Bambi. O sacrifício, a coragem, o zelo e a coletividade de uma comunidade familiar são os semas centrais nesse aspecto temático da Disney.

\footnotetext{
${ }^{9}$ Disney PRESENTS THE ADVENTURE, THE MAGIC, THE MUSIC. EXPERIENCE THE GREATEST DISNEY ANIMATED EVENT SINCE “THE LION KING”. FROM THE CREATOR OF “TANGLED”, THIS HOLIDAY SEASON, THE POWER OF FAMILY IS THE STRONGEST MAGIC OF ALL: DISNEY "FROZEN".

${ }^{10}$ É possível que se leia esse texto em uma época que, no Brasil, o termo "família tradicional”, incluído no discurso político, esteja saturado, uma vez que tende a se opor ao avanço dos direitos igualitários para casais homossexuais. Na Disney, entretanto, é importante mencionar, por mais que não seja o objetivo central aqui, falar em família ou tradicionalidade não permite que misturemos seu discurso com o discurso político brasileiro desses anos de 2010 livremente. Nota-se, em Frozen, uma séria depreciação do casamento heterossexual, por exemplo, que passa a ser tomado com disforia em mais de metade do filme e isso não impede que o enunciador chame os personagens que rejeitam o casamento de família com sentido de tradicionalidade, retomando aquele conjunto de semas que se relacionam ao zelo e ao afeto.
} 
Mas a maior transformação na identidade Disney está no modo como o enunciador constrói a si mesmo. Se em Aladdin já não havia distinção entre enunciador e Walt Disney como em Bambi, em Frozen, não existe Walt Disney, apenas Disney, e o enunciador não tem voz, apenas escreve. Retirar a voz é retirar um elemento identificatório, que permite que se diga se é um homem ou mulher, jovem ou não, um ou muitos, passando a se definir como um enunciador mais genérico e menos marcado. A escrita neutraliza esses aspectos, mas não deixa de referenciar um "tu” explícito, quando usa o imperativo "experience”.

Por fim, parece-nos que cada vez mais o ethos Disney se define por aquilo que ele foi, ou seja, continua sendo como era e o enunciatário reconhece essa maneira de ser histórica. Aladdin faz questão de citar seus dois antecessores e Frozen cita Enrolados e O Rei Leão (de 20 anos antes, 1994). O ethos destes filmes compartilha as características com o trailer do filme, criando a imagem-fim da totalidade de discursos, ou o ethos baseado em estereótipos sociais. Não que a Disney não se valha de estereótipos e estilos saturados para se definir, mas, com tanto tempo de vida pública, a própria Disney tornouse um estereótipo, homogeneizando aqueles elementos de caráter todos (a imaginação, a magia, o altruísmo, a intensidade, a família) em um só sema, o sema “Disney”. Por isso o substantivo tornou-se adjetivo.

E por isso fizemos questão de citar outras grandes empresas do ramo da ficção hollywoodiana, porque mesmo que algumas delas sejam mais antigas que a Disney, não parece que nenhuma tornou-se um sema, um signo, tornou-se um ethos, arquienunciador, imagem-fim, mundo ético, estilo, estereótipo tão bem definido como a empresa de Walt.

\begin{abstract}
Mais além, o ethos implica uma maneira de se mover no espaço social, uma disciplina tática do corpo apreendida através de um comportamento. O destinatário a identifica apoiando-se num conjunto difuso de representações sociais avaliadas positiva ou negativamente, em estereótipos que a enunciação contribui para confrontar ou transformar: o velho sábio, o jovem executivo dinâmico, a mocinha romântica... (MAINGUENEAU, 2008, p. 18)
\end{abstract}

Em meados do século XX, o ethos Disney confrontou os estereótipos suscitados para construção de sua identidade. No século XXI, depois de mais de cinquenta anos, os estereótipos foram totalmente assimilados, e a Disney passou a ser uma representação social mais ou menos estável, estereótipo de si mesma, mais ou menos positiva ou 
negativa, que pode ou não ser suscitada por outros ethe ou, como ocorre, ser suscitada por si mesma em seus novos trailers, para dizer que continua sendo a mesma.

\section{O ethos Disney}

Após a análise e reflexão, podemos traçar características marcantes desse ethos Disney. Comentamos brevemente os aspectos estadunidenses nos trailers, mas é preciso que formalizemos a presença do ideal American Dream, o Sonho Americano, em que o indivíduo pode conquistar seu sucesso por meio de seu próprio esforço. Os personagens da Disney alcançam a felicidade por meio de esforço próprio e pela sua imaginação e inovação.

Existem, certamente, elementos de todos esses apelos no trabalho de Disney, e sua enorme popularidade é, sem dúvida, o resultado de uma combinação de fatores - na verdade, a habilidade de Disney para reunir muitas coisas díspares e até tendências contraditórias. [...]

Se uma das origens da mágica de Disney foi sua habilidade de mediar entre o passado e o futuro, a tradição e a iconoclastia, o rural e o urbano, o indivíduo e a comunidade e até entre o conservadorismo e o liberalismo. Sua mais poderosa fonte de atração e seu maior legado podem ser o fato de Walt Disney [...] ter definido os parâmetros de realização dos desejos e demonstrar em grande escala para seus conterrâneos norte-americanos e, finalmente, para o mundo inteiro, como uma pessoa pode tornar-se mais forte pelo uso da imaginação. (GABLER, 2009, p. 11-12)

De maneira mais específica, essas ações inovadoras, imaginativas e o esforço próprio são a medida do viver intensamente, do viver ativamente. A vida ativa opõe-se à vida passiva, e ao simulacro de "outro" que é feito na enunciação, são atribuídas características neutras, átonas e passivas. Dessa maneira, o “outro” da Disney seria aquele que não se entrega ao sonho, ao amor, às emoções individuais, que não arrisca tudo em prol do bem-estar de outros sujeitos, não é altruísta, não usa a imaginação etc. Lembramos que essas identidades são construídas na enunciação e pertencem à semiosfera, não à esfera política do mundo real. A Disney constrói para si a imagem que vê de si ou a que quer mostrar de si, assim como a imagem do “outro” é a ela que vê ou quer mostrar do outro. O sentido não tem compromisso com a verdade, porque nele não há parâmetros 
exatos de verdade ou mentira, mas sim parâmetros de eficácia argumentativa, à medida que o enunciatário se convence ou não do que é dito (ethos) e do que é calado (“outro”).

Guiando-nos pelo conceito de corporificação do ethos do estilo, da imagem-fim, na Disney, o ator da enunciação ganha até mesmo um nome, o nome de Walt Disney, é figurativizado, o que facilita enxergar um corpo base que serve de tática de controle para o corpo assumido pelo enunciatário. Por isso, com muita naturalidade, fala-se que algo é “a cara da Disney”, ou então "lições que a Disney ensinou”, sem se referir especificamente ao departamento de animação, ou a presidência da companhia, e sim a uma entidade corpórea, antropomorfizada, que, de alguma forma fantasma, como apontado por Maingueneau (1997, p. 47), rege e coordena tudo que leva a assinatura Disney. Trata-se do estágio de estereotipação do estilo, Up, da virtualização e da atenuação da presença. É como se construíssemos uma imagem mental do velho Walt Disney (o homem), que se senta para nos contar uma história a cada filme. Se nós imaginamos Walt contando a história, vivendo em seu contexto sócio-histórico, nos Estados Unidos do século XX, enfrentando uma crise econômica e apegando-se à filosofia do sonho americano, imaginamos a nós mesmos sentados e atentos, como enunciatário construído, enquanto espectadores de sua obra, apegando-se a esse mesmo sonho, superando as dificuldades do mundo do progresso.

Naturalmente, os analistas buscam explicações sempre que alguém consegue implantar-se na cultura e na psique americanas tão profundamente quanto Walt Disney. No seu caso, destacaram a aparente inocência de seu trabalho, a suave restauração da confiança, [...], a fé ingênua na perseverança e na vitória [...]. Tanto na imaginação de Disney quanto na imaginação americana [...]; era possível, usando o próprio poder, ou, mais exatamente, mediante o poder da bondade inata, alcançar o sucesso. [...] De forma semelhante, tanto na imaginação de Disney quanto na imaginação americanas, a perfeição era uma meta conquistável. (GABLER, 2009, p. 10, 14)

Mas essa impressão é instável e parcialmente velada pela própria Disney. É na imagem do homem que cremos estar a alma desse estilo, porque é o ponto em que os ethe dos três trailers mais diferem. Em Bambi, o enunciador se refere a Walt Disney, homem, o contador de histórias. Em Aladdin, quem produziu o filme-objeto-valor é a Walt Disney Pictures, que remete aos estúdios de animação nomeados com o nome de seu fundador. 
Já em Frozen, fala-se apenas em Disney, sem especificar se se trata dos estúdios, sugerindo uma entidade mais ampla que responde por toda a corporação.

Chamar de Disney ao invés de Walt Disney pode, sim, ser uma tentativa de estabelecer esse corpo amplo que representa todas as divisões e departamentos, filmes e outros produtos, como brinquedos, roupas, materiais, os parques, todos estampados com “Disney”, tudo pertencendo a uma só fonte, a um só totus. Desse totus, os filmes seriam um unus de estilo, e outros unus seriam os filmes individualmente tomados. O ethos, então, aponta para uma generalidade, um mundo ético inteiro, um coletivo de diversidades assemelhadas sob o título Disney. O mundo ético e o ethos estariam organizados segundo esses princípios, de respeito à diversidade à medida em que todos se unem em um nome comum, com um objetivo comum, como ocorre com os atores dos enunciados dos filmes: viver com intensidade e imaginação o sonho americano.

Desvincular-se da imagem do homem Walt Disney para ser A Walt Disney e, posteriormente, A Disney também reforça a ideia de pertencer a uma coletividade, de não ser individual, amenizando, apagando um pouco o nacionalismo americano, dirigindo-se para um público global. Mantém, sem dúvida, a filosofia do American dream, mas a expande e a internacionaliza. O mundo ético a que pertence o ethos e o fiador é um grupo de enunciatários, corpo coletivo, um arquienunciatário, não reunido como diversidade ao redor dos EUA, mas, sim, reunido em seus próprios países, em suas salas com TVs, etc., assemelhando-se não necessariamente frente à história de Walter Elias Disney e sua filosofia, mas frente à amplitude multicultural da Disney e sua filosofia base do sonho americano dividida com o resto do planeta.

Em outras palavras, para que o ethos de Walt Disney fosse globalizado, foi preciso que a Disney se tornasse seu arquienunciador um sujeito mais genérico, tornar-se estereótipo, que ainda vive da saturação de seus enunciados passados.

\section{Considerações finais}

Todos esses sentidos são possíveis. O que não muda é o viver intensamente e todas as suas implicações, é o esforço próprio, altruísmo, família, e imaginação e a cada vez mais presente tendência da Disney de pertencer a uma comunidade mundial. 
Muito tempo se passou desde que Walt produziu, na época da Segunda Guerra, seu icônico curta-metragem, Der Fuehrer's face ${ }^{11}$, de um Pato Donald trajado com um uniforme nazista e vivendo trapalhadas em uma instalação alemã que, depois de constatar que tudo era um sonho, saúda a bandeira americana em seu quarto. Muito tempo se passou desde que a Disney, Walt Disney, ou empresa do Walt Disney, nasceu como representante de um povo e de uma nação. De certo, os elementos semióticos daquela nação ainda estão presentes, porque são a gênese de tudo isso, mas a tentativa nata é de globalização, consoante com o mundo político e semiótico atual. Consome-se muita cultura estadunidense hoje em dia, e é natural que, se os EUA pretendem continuar vendendo seus objetos-valor para o mundo, eles próprios se façam mais mundiais. São esquemas semióticos que nos auxiliam a compreender a enunciação desse material artístico.

Pelo menos, esse é o efeito de sentido do abrangente ethos norte-americano, uma espécie de hiperônimo do ethos Disney. Sentido que aponta para o multiculturalismo, e em inúmeros discursos, principalmente nos discursos norte-americanos, veremos esse simulacro presente, como nas palavras de dois dos maiores animadores da Disney, Ollie Johnston e Frank Thomas, que trabalharam com o próprio Walt em pessoa:

A popularidade dos filmes da Disney ao redor do mundo é prova de que os valores do entretenimento são similares em todo lugar, independente da geografia e diferenças culturais. Pessoas são pessoas, tanto faz onde vivem, e enquanto elas podem ser atraídas por uma ampla variedade de atividades e assuntos, a única coisa que sempre interessa para elas mais que tudo são elas mesmas. (JOHNSTON; THOMAS, 1981, p. 535, tradução nossa $)^{12}$

Assim, compreendemos que, na totalidade estilística Disney, subjacente ao estilo norte-americano, há uma ideia eufórica de uma grande comunidade identitária de seres humanos dispostos passionalmente à intensidade do viver, de um mundo ético coletivo exemplar.

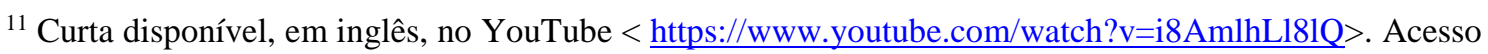
em: 26 jul. 2015

12 The popularity of the Disney films around the world is proof that entertainment values are similar everywhere, in spite of geography and cultural differences. People are people, wherever they live, and while they may be attracted to a broad variety of activities and subjects, the one thing that always interests them the most is themselves.
} 
SILVA JUNIOR, Mário Sérgio Teodoro da. Style and ethos on Disney: changings in identity. Revista do Gel, São Paulo, v. 14, n. 1, p. 288-308, 2017.

\begin{abstract}
In the last few years, Discursive Semiotics has brought to its theoretical ideas some contributions to study the concept of style, found in Discini's (O estilo nos textos: histórias em quadrinhos, mídia e literatura (2013) and Corpo e estilo (2015)), allowing reflections about identity, otherness and the manner of acting of a Subject (enunciator) in the real world and in the semiotic world. Among the numerous enunciatives identities from the texts' nowadays worldwide scenario, Walt Disney's identity, the Animation Studios, is one of the most temporally resilient, with more than 70 years and with great popular acceptance. In this paper, we want to verify how a single style can remain so constant and current for all these years. In despite of issues about ethos and Discini's work (2013), we will use to the original concept of ethos proposed by Maingueneau in (2007), Novas tendências em análise do discurso (1997) and in A propósito do ethos (2008). Given the extension of our work, we selected three trailers from Disney's movies that covers the period from 1942, with Bambi's trailer, to 1992, with the musical Aladdin's one, and to 2013, with Frozen. By the analysis of these pieces, we can point out the way Disney's enunciator puts himself in the social world, how he defines his enunciate, how he also defines another subject with whom he doesn't identify with and, at last, expressing an ethical positioning in the social world..
\end{abstract}

Keywords: Style. Ethos. Semiotics.

Submetido em: 02/04/2016.

Aceito em: 12/07/2016.

\title{
Referências
}

ALADDIN trailer. YouTube. Disponível em: <https://www.youtube.com/watch?v=QapaqcDucmg> Acesso em: 25 jul. 2015.

DISCINI, N. O estilo nos textos: história em quadrinhos, mídia e literatura. 2. ed. São Paulo: Contexto, 2013.

Corpo e estilo. São Paulo: Contexto, 2015.

FROZEN Official Elsa Trailer (2013) - Disney Animated Movie HD. YouTube. Disponível em: <https://www.youtube.com/watch?v=FLzfXQSPBOg>. Acesso em: 25 jul. 2015.

GABLER, N. Walt Disney - o triunfo da imaginação americana. Tradução de Ana Maria Mandim. São Paulo: Novo Século, 2009. 
GREIMAS, A. J.; COURTÉS, J. Dicionário de semiótica. Tradução de Alceu Dias Lima et al. 2. ed. São Paulo: Cultrix, 2013.

JOHnStOn, O.; THOMAS, F. The illusion of life - Disney Animation. New York: Disney Editions, 1981.

MAINGUENEAU, D. Novas tendências em análise do discurso. Tradução de Freda Indursky. 3. ed. Campinas: Pontes; Editora da Universidade Estadual de Campinas, 1997.

A propósito do ethos. In: MOTTA, A. R.; SALGADO, L. (Org.). Ethos discursivo. São Paulo: Contexto, 2008. p. 11-29.

(ORIGINAL 1942) Bambi Trailer. YouTube. Disponível em: <https://www.youtube.com/watch?v=nLvX-erABqY>. Acesso em: 25 jul. 2015.

STEWART, J. B. Disney war - a guerra pelo controle da maior empresa de entretenimento do mundo. Tradução de Ana Carolina Mesquita et al. Rio de Janeiro: Ediouro, 2006.

SURRELL, J. O Segredo dos roteiros da Disney - dicas e técnicas para levar magia a todos os seus textos. Tradução de Beatriz Sidou. São Paulo: Panda Books, 2009.

WAKING sleeping beauty. Direção de Don Hahn. Produção de Don Hahn, Connie N. Thompson e Peter Schneider. Stone Circle Productions, 2009. 1 DVD (86 min.), son., color. 